CARDIOVASCULAR MEDICINE

\title{
Markers of inflammation and multiple complex stenoses (pancoronary plaque vulnerability) in patients with non-ST segment elevation acute coronary syndromes
}

\author{
P Avanzas, R Arroyo-Espliguero, J Cosín-Sales, G Aldama, C Pizzi, J Quiles, J C Kaski
}

Heart 2004;90:847-852. doi: 10.1136/hrt.2003.015826

See end of article for authors' affiliations

Correspondence to: Professor Juan C Kaski, Cardiological Sciences, Coronary Artery Disease Research Unit, St George's Hospital Medical School, London SW17 ORE, UK; jkaski@sghms.ac.uk

Accepted 6 November 2003

\begin{abstract}
Objective: To assess the relation between markers of inflammation and the presence of multiple vulnerable plaques in patients with non-ST segment elevation acute coronary syndromes.

Design: Prospective cohort study of 55 patients with non-ST segment elevation acute coronary syndromes and angiographically documented coronary disease. Blood samples were obtained at study entry for the assessment of high sensitivity $C$ reactive protein (CRP), neopterin, and neutrophil count. Coronary stenoses were assessed by quantitative computerised angiography and classified as "complex" (irregular borders, ulceration, or filling defects) or "smooth" (absence of complex features). Extent of disease was also assessed by a validated angiographic score.

Results: Neutrophil count $(r=0.36, p=0.007), C R P$ concentration $(r=0.33, p=0.02)$, and neopterin concentration $(r=0.45, p<0.001)$ correlated with the number of complex stenoses. Patients with multiple (three or more) complex stenoses, but not patients with multiple smooth lesions, had a higher neutrophil count $\left(5.9(1.4) \times 10^{9} / \mathrm{l} \vee 4.8(1.4) \times 10^{9} / \mathrm{l}, \mathrm{p}=0.02\right)$, CRP concentration (log transformed) (1.08 (0.63) $\vee 0.6(0.6), p=0.03)$, and neopterin concentration (log transformed) 0.94 $(0.18) \vee 0.79(0.15), p=0.002)$. Multiple regression analysis showed that neopterin concentration $(B=4.8,95 \%$ confidence interval $(C I) 1.9$ to $7.7, p=0.002)$ and extent of coronary artery disease $(B=0.6,95 \% \mathrm{Cl} 0.03$ to $1.2, p=0.04$ ) were independently associated with the number of complex stenoses.

Conclusions: Acute inflammatory markers such as high neutrophil count, CRP concentration, and neopterin concentration correlate with the presence of multiple angiographically complex coronary stenoses. Neopterin concentration was a stronger predictor of multiple complex plaques than were neutrophil count and CRP concentration. These findings suggest that a relation exists between inflammation and pancoronary plaque vulnerability.
\end{abstract}

A cute coronary syndromes (ACS) are usually associated with "vulnerable" atheromatous plaques, which are prone to fissuring or to developing endothelial erosion. ${ }^{12}$ At angiography, disrupted or ulcerated plaques often appear as "complex" stenoses with rough contours or "filling defects" suggestive of intracoronary thrombosis. ${ }^{3-6}$ The presence of multiple complex coronary plaques is known to be associated with adverse prognosis in patients with coronary artery disease. ${ }^{7}$ Inflammation appears to play an important part in plaque vulnerability and disruption. White blood cell activation and the subsequent release of proinflammatory cytokines can promote rupture or erosion of atheromatous coronary plaques through a number of mechanisms. ${ }^{12}$ Inflammatory markers such as $\mathrm{C}$ reactive protein (CRP), neutrophil count, and neopterin are increased in patients with ACS and are markers of coronary artery disease activity. ${ }^{8}{ }^{9}$ Moreover, previous reports from our group showed that neopterin concentration correlates with the presence of complex stenoses in patients with unstable angina. ${ }^{10}$

Previous work by Buffon and colleagues ${ }^{11}$ and Rioufol and associates $^{12}$ suggests that ACS is a pancoronary condition associated with multiple plaque vulnerability. We therefore sought to study the relation between inflammatory markers and the presence of multiple complex (vulnerable) plaquesthat is, those most at risk of recurrent events in patients presenting with ACS.

\section{METHODS}

\section{Patients}

We studied 55 of 106 consecutive patients who were admitted to the coronary care unit of St George's Hospital in London between September 1996 and June 1997 with non-ST segment elevation ACS and whose condition stabilised rapidly with medical treatment. All patients in the study had angiographically documented coronary artery disease and had no evidence of local or systemic inflammatory conditions. Excluded were 40 patients without angiography, seven patients with systemic inflammatory conditions, and four with creatinine concentration $\geqslant 120 \mathrm{mmol} / \mathrm{l}$. The latter were excluded because renal function is a major determinant of blood neopterin concentration. Cardiac troponin was measured for only 32 patients, as this marker was not routinely measured in our institution at the time of the study. The patients' clinical management and the decision to proceed to cardiac catheterisation were left to the discretion of the managing cardiologists, who were unaware of results regarding inflammatory markers. Some patients in the present study had been enrolled in a previous study by our group. ${ }^{10}$ All patients had primary unstable angina, corresponding to subclass " $\mathrm{b}$ " of Braunwald's classification. ${ }^{13}$ Forty seven patients were in Braunwald class IIIb and eight were in class IIb. Cardiac troponin T was abnormal in 10 of the 32 patients tested. All patients had transient ECG changes that were diagnostic of myocardial ischaemia and 
received treatment with aspirin (75-325 mg), heparin, intravenous glyceryl trinitrate, and $\beta$ blockers. All patients gave written informed consent before study entry and the study was approved by the local research ethics committee.

\section{Blood sampling, neutrophil count, CRP, and neopterin measurements}

Blood samples from every patient were drawn at admission to the coronary care unit. Neutrophils were counted by an automated blood cell counter. Blood for CRP measurement was drawn and centrifuged immediately and the serum aliquoted and stored at $-80^{\circ} \mathrm{C}$ until analysis. No specimen inadvertently thawed during storage. CRP was measured on the COBAS Integra (Roche Diagnostics Limited, Lewes, East Sussex, UK) with the CRP latex assay in both the high sensitivity application (analytical range $0.2-12 \mathrm{mg} / \mathrm{l}$ ) and the normal application (analytical range 2-160 mg/l). The analytical precision of the high sensitivity CRP latex assay was $7.6 \%$ at a concentration of $1.02 \mathrm{mg} / \mathrm{l}, 3.3 \%$ at $1.79 \mathrm{mg} / \mathrm{l}$, and $1.3 \%$ at $4.36 \mathrm{mg} / \mathrm{l}$. Samples outside the analytical range of the high sensitivity CRP latex assay were analysed by the CRP latex assay in the normal application. The analytical precision of the normal CRP latex assay was $2.4 \%$ at a concentration of $29.5 \mathrm{mg} / \mathrm{l}$ and $1.3 \%$ at $113 \mathrm{mg} / \mathrm{l}$. Serum neopterin concentration was measured with a commercially available immunoassay (ELISA kit, IBL, Hamburg, Germany). The within coefficient variability in the $7.7 \mathrm{nmol} / \mathrm{l}$ range was less than $3 \%$ and was below $4 \%$ in the $20 \mathrm{nmol} / \mathrm{l}$ range.

\section{Angiographic analyses}

Coronary angiography was carried out according to the Judkins technique. Images of the coronary tree of all patients were obtained in routine, standardised projections with the digital quantitative Philips Integris 3000 system (Philips, the Netherlands). Two experienced cardiologists who had no knowledge of the patients' clinical characteristics and biochemical results visually reviewed all angiographic images to assess the extent of coronary artery disease and to characterise the morphology of all coronary artery stenoses with $\geqslant 30 \%$ diameter reduction.

\section{Angiographic scoring system}

To assess coronary artery disease extent and severity, angiograms were scored according to the number of major coronary arteries with $\geqslant 75 \%$ reduction in lumen diameter (vessel score). Interobserver variability (the standard deviation of the mean unsigned difference between paired estimates) for the vessel score in this study was $4.9 \%$.

\section{Angiographic coronary stenosis morphology}

Lesion morphology was assessed in all stenoses with $>30 \%$ diameter reduction as reported in previous studies by our group and others. ${ }^{14-19}$ Briefly, stenoses were subdivided into complex or smooth. Complex lesions were defined by the following features: (a) irregular morphology, scalloped borders, or both; (b) overhanging or abrupt edges perpendicular to the vessel wall; (c) ulceration (that is, outpouchings within the stenosis); and (d) the presence of filling defects consistent with intracoronary thrombus. Of interest, $88 \%$ of coronary stenoses defined as complex corresponded to type $\mathrm{C}$ in the American College of Cardiology/American Heart Association classification. ${ }^{20}$ Coronary stenoses with no complex features were classified as smooth lesions. When discrepancies arose regarding the morphological appearance of a lesion, a third experienced observer examined the stenosis and the lesion was classified by consensus. The reproducibility of the findings was determined by repeat analysis more than three months later by two experienced observers who had no knowledge of the results of stenosis classification obtained at the first reading. Interobserver agreement regarding qualitative morphological analyses was $97 \%$.

\section{Statistical analysis}

Normality was analysed with the Kolmogorov-Smirnov test. CRP and neopterin serum concentrations had a non-normal distribution and were therefore log transformed before analysis. Results for normally distributed continuous variables are expressed as mean (SD) and continuous variables with non-normal distribution are presented as median value (interquartile interval). Comparisons of continuous variables were analysed by the unpaired $t$ test. The Spearman two way test was used to assess the relation between two quantitative variables with non-normal distribution. The Pearson two way test was used to assess the relation between two quantitative variables with normal distributions. We assessed independent predictors of complex stenoses with multiple regression analysis. In the multiple regression analysis the dependent variable was the number of complex lesions; the independent variables were those that, on univariate analysis, correlated significantly with the number of complex lesions and variables that showed a trend $(p<0.20)$ towards an association. Differences were considered to be significant if the null hypothesis could be rejected with $>95 \%$ confidence. The SPSS 11.5 statistical software package (SPSS Inc, Chicago, Illinois, USA) was used for all calculations.

\section{RESULTS}

Table 1 shows the baseline clinical and biochemical characteristics and table 2 the angiographic results of the 55 patients in the study. Complex lesions were found in 44 (80\%) patients, of whom 15 had multiple (three or more) complex lesions in one or more coronary arteries. Smooth

\begin{tabular}{|c|c|}
\hline & Mean (SD) or $n(\%)$ \\
\hline Age (years) & $62.5(10.5)$ \\
\hline Male sex & $41(74.5 \%)$ \\
\hline Systolic blood pressure $(\mathrm{mm} \mathrm{Hg})$ & $138.9(19.7)$ \\
\hline Diastolic blood pressure $(\mathrm{mm} \mathrm{Hg})$ & $77.1(14.3)$ \\
\hline Body mass index $\left(\mathrm{kg} / \mathrm{m}^{2}\right)$ & $26.8(4.1)$ \\
\hline Previous PTCA & $14(25.5 \%)$ \\
\hline Previous myocardial infarction & $31(56.4 \%)$ \\
\hline Previous unstable angina & $28(50.9 \%)$ \\
\hline Previous stroke & $3(5.5 \%)$ \\
\hline \multicolumn{2}{|l|}{ Cardiovascular risk factors } \\
\hline Diabetes mellitus & $7(12.7 \%)$ \\
\hline Hyperlipidaemia* & $27(49.1 \%)$ \\
\hline Hypertension & $29(52.7 \%)$ \\
\hline Smoking & $14(25.5 \%)$ \\
\hline \multicolumn{2}{|l|}{ Biochemistry } \\
\hline Cholesterol (mmol/l) & $5.4(1)$ \\
\hline HDL cholesterol (mmol/l) & $1(0.3)$ \\
\hline LDL cholesterol (mmol/l) & $3.4(0.8)$ \\
\hline Triglycerides (mmol/l) & $1.7(1)$ \\
\hline \multicolumn{2}{|l|}{ Treatment } \\
\hline Aspirin & 40 (72.7\%) \\
\hline$\beta$ Blockers & $24(43.6 \%)$ \\
\hline Nitrates & $27(49.1 \%)$ \\
\hline Calcium channel antagonists & $30(54.5 \%)$ \\
\hline ACE inhibitors & $10(18.2 \%)$ \\
\hline HMG-CoA reductase inhibitors & $13(23.6 \%)$ \\
\hline
\end{tabular}

*Total cholesterol $>5.4 \mathrm{mmol} / \mathrm{l}$.

$\mathrm{ACE}$, angiotensin converting enzyme; $\mathrm{HDL}$, high density lipoprotein HMG-COA, hydroxymethyl glutaryl coenzyme A; LDL, low density lipoprotein; PTCA, percutaneous transluminal coronary angioplasty. 
Table 2 Inflammatory markers and angiographic variables in 55 patients with acute coronary syndromes

\begin{tabular}{ll}
\hline Variable & $\begin{array}{l}\text { Mean (SD) or } \\
\text { median (IQR) }\end{array}$ \\
\hline Inflammatory markers & \\
White blood cell count $\left(\times 10^{9} / \mathrm{I}\right)$ & $8(1.7)$ \\
Neutrophil count $\left(\times 10^{9} / \mathrm{I}\right)$ & $5.1(1.5)$ \\
Log $_{10}$ neopterin & $0.81(0.03)$ \\
Log $_{10}$ CRP & $0.7(0.64)$ \\
Angiography & $2.0(1-3)$ \\
Vessel score & $3.5(1.8)$ \\
Number of smooth stenosis & $1.7(1.5)$ \\
Complex stenosis (units) & $59.1(14.9)$ \\
Ejection fraction (\%) & \\
\hline CRP, C reactive protein; IQR, interquartile range. & \\
\hline
\end{tabular}

lesions were observed in 53 (96.4\%) patients, 35 of whom had multiple (three or more) smooth lesions.

Neutrophil count, CRP concentration, and neopterin concentration correlated significantly with the number of complex stenoses but not with the number of smooth coronary lesions (table 3). Of the three markers assessed, neopterin was most strongly correlated with the number of complex stenoses. As neopterin concentration is known to be influenced by age, neopterin concentrations were adjusted by age and reanalysed.

Patients with multiple complex stenoses had higher neutrophil count, CRP concentration, and neopterin concentration than patients with fewer than three complex lesions. Concentrations of the three inflammatory markers where similar in patients with multiple smooth lesions and patients with fewer than three smooth stenoses (fig l).

Univariate analysis showed that age, low density lipoprotein cholesterol concentration, and vessel score were significantly correlated with the number of complex lesions in our patients (table 4). Backward stepwise multiple regression analysis was performed with, firstly, all three inflammatory markers; secondly, variables significantly related to complex stenosis on univariate analysis; and thirdly, variables showing a trend $(\mathrm{p}<0.20)$ towards an association. Neopterin concentration and vessel score were the only two variables that remained independent predictors of the number of complex lesions in this model (table 5). Multivariate analysis, without the inclusion of neopterin in the model, showed that neutrophil count and vessel score, but not CRP, were independent predictors of the number of complex lesions (data not shown).

Table 3 Univariate correlation between neutrophil count, CRP concentration, and neopterin concentration (both log transformed), and angiographic data

\begin{tabular}{|c|c|c|}
\hline & $r$ & p Value \\
\hline \multicolumn{3}{|l|}{ Neutrophil count } \\
\hline Vessel score ${ }^{*}$ & 0.10 & 0.43 \\
\hline Number of complex stenoses & 0.36 & 0.007 \\
\hline Number of smooth stenoses & 0.03 & 0.81 \\
\hline Ejection fraction (\%) & 0.16 & 0.29 \\
\hline \multicolumn{3}{|l|}{ Log10 CRP } \\
\hline Vessel score* & 0.26 & 0.07 \\
\hline Number of complex stenoses & 0.33 & 0.02 \\
\hline Number of smooth stenoses & 0.12 & 0.40 \\
\hline Ejection fraction (\%) & -0.003 & 0.98 \\
\hline \multicolumn{3}{|l|}{ Log10 neopterint } \\
\hline Vessel score* & 0.09 & 0.51 \\
\hline Number of complex stenoses & 0.45 & $<0.001$ \\
\hline Number of smooth stenoses & 0.004 & 0.97 \\
\hline Ejection fraction (\%) & 0.13 & 0.4 \\
\hline
\end{tabular}

\section{DISCUSSION}

The main finding of the present study is that the presence of multiple vulnerable plaques is associated with increased concentrations of inflammatory markers. These findings suggest a link between inflammation and pancoronary plaque vulnerability. In our study, inflammatory markers such as neutrophil count, CRP, and neopterin correlated significantly with multiple plaque complexity. Neopterin was the strongest predictor of multiple plaque complexity. Thus, inflammatory markers as measured in our study identify a vulnerable phenotype among patients with non-ST segment elevation ACS.

\section{Inflammatory markers and angiographic complexity} A previous study from our group showed that neopterin concentration is a predictor of the presence of complex stenoses in patients with unstable angina. ${ }^{10} \mathrm{~A}$ recent study from Zairis and colleagues ${ }^{21}$ reported that CRP concentration correlated with stenosis complexity in patients with unstable angina. They studied 228 patients with primary unstable angina and found that CRP concentration was independently associated with the presence of either multiple stenosis or angiographically apparent thrombus containing complex lesions. Katritsis and colleagues ${ }^{22}$ linked CRP concentration to various angiographic characteristics in 103 patients undergoing cardiac catheterisation for suspected coronary artery disease. They found higher CRP concentration among patients with macroscopic thrombus without total occlusion of the vessels than among patients without thrombus and total vessel occlusion. Sabatine and colleagues ${ }^{23}$ correlated angiographically apparent thrombus with increasing white blood cell count in patients with unstable angina. Unfortunately, they did not assess the relation between neutrophil count and plaque complexity. The present study is the first to assess specifically the relation between three inflammatory markers and the presence of multiple angiographically complex lesions in patients with non-ST segment elevation ACS. Our study lends support to the hypothesis that inflammation may be responsible for a pancoronary process leading to the development of multiple complex lesions in individual patients. We showed here that neutrophil count, $\mathrm{CRP}$, and neopterin were predictors of multiple angiographically complex lesions suggestive of plaque disruption, with neopterin being the strongest predictor after adjusting for confounding factors. Of importance, no differences were found in inflammatory marker concentrations between patients with and those without multiple smooth lesions. This finding further strengthens the argument that inflammation influences the presence of a vulnerable phenotype and this in turn appears to be a pancoronary process.

\section{Inflammation, macrophages, and neopterin}

Findings in this study confirm and expand previous observations from our group regarding neopterin as a predictor of multiple complex lesions in patients with unstable angina. ${ }^{10}$ Several studies have previously shown that macrophages play a key part in destabilising atheromatous plaques. ${ }^{1224}$ Neopterin is a pteridine derivative that is secreted by macrophages after stimulation by interferon $\gamma .^{25}$ It has been suggested that complex lesions seen on angiography are vulnerable plaques prone to disruption or actually disrupted plaques. ${ }^{1426} 27$ Plaque vulnerability has been shown to be a function of the increased local number of inflammatory cells within plaques, particularly macrophages and activated lymphocytes. ${ }^{28}$ Activated lymphocytes in atherosclerotic plaques produce interferon $\gamma$, a molecule that reduces collagen synthesis within atheromatous plaques and activates macrophages. Activated macrophages synthesise and release matrix metalloproteinases, which contribute to 

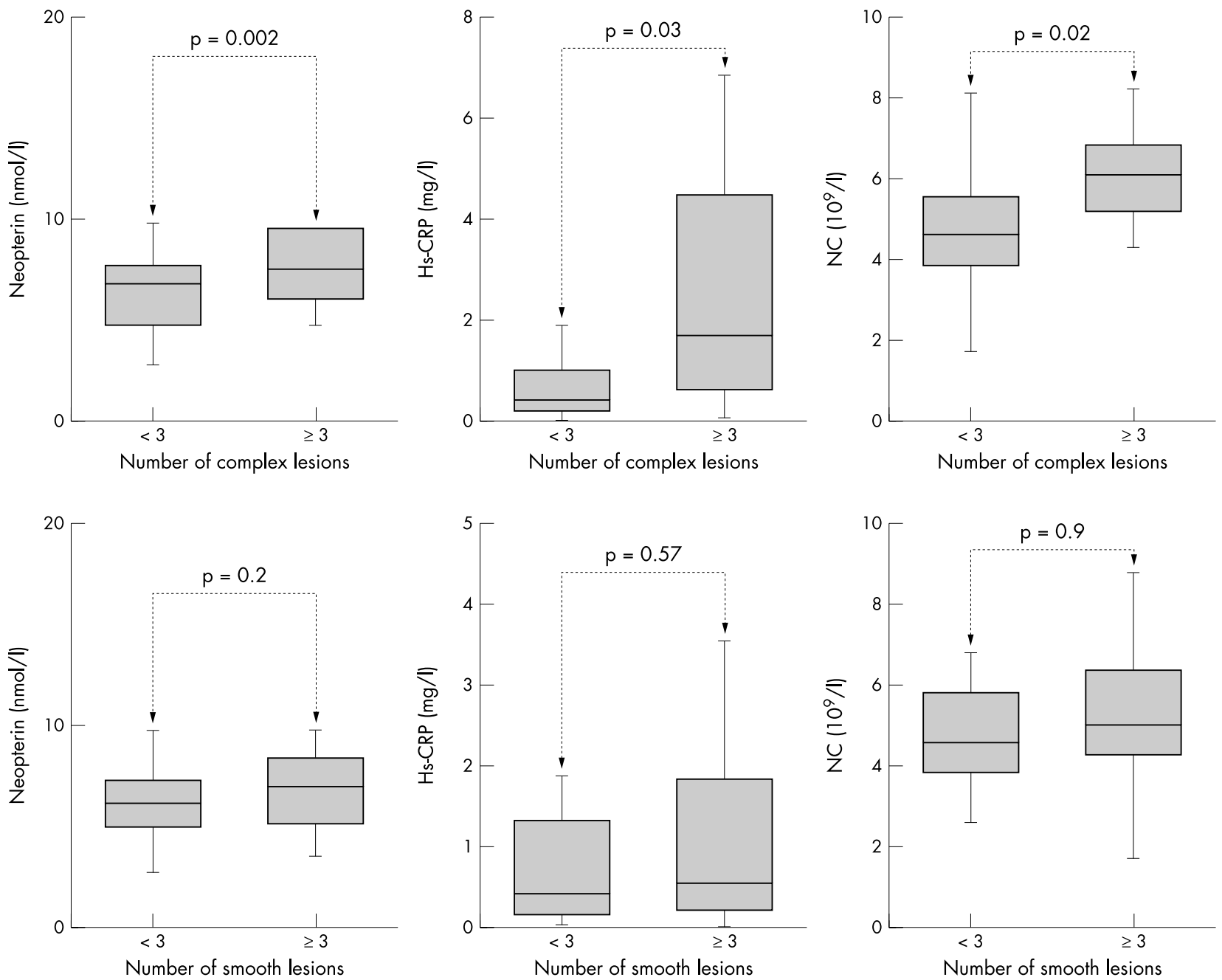

Figure 1 Box plots showing differences in neopterin concentration, high sensitivity $\mathrm{C}$ reactive protein $(\mathrm{Hs}$ - $\mathrm{CRP}$ ) concentration, and neutrophil count (NC) between patients with multiple complex lesions ( $\geqslant 3$ ) and those without, and between patients with multiple smooth lesions ( $\geqslant 3$ ) and those without.

the degradation of collagen in the fibrous cap. ${ }^{29}$ These processes result in an imbalance between synthesis and degradation of matrix components in areas of active inflammation within atherosclerotic plaques ("vulnerable sites"), which favours plaque rupture. ${ }^{30} 31$ Macrophages activated by interferon $\gamma$ synthesise neopterin, ${ }^{25}$ which, in

Table 4 Univariate correlation ( $r$ ) between baseline variables and complex coronary artery stenosis

\begin{tabular}{|c|c|c|}
\hline & $r$ & p Value \\
\hline Age (years) & 0.42 & 0.001 \\
\hline Body mass index $\left(\mathrm{kg} / \mathrm{m}^{2}\right)$ & 0.04 & 0.78 \\
\hline Systolic blood pressure $(\mathrm{mm} \mathrm{Hg})$ & 0.18 & 0.18 \\
\hline Diastolic blood pressure $(\mathrm{mm} \mathrm{Hg})$ & -0.02 & 0.88 \\
\hline \multicolumn{3}{|l|}{ Biochemistry } \\
\hline Cholesterol (mmol/l) & 0.10 & 0.44 \\
\hline HDL cholesterol (mmol/l) & -0.16 & 0.26 \\
\hline LDL cholesterol (mmol/l) & 0.34 & 0.02 \\
\hline Triglycerides (mmol/l) & -0.005 & 0.97 \\
\hline White blood cell count $\left(\times 10^{9} / \mathrm{l}\right)$ & 0.10 & 0.45 \\
\hline \multicolumn{3}{|l|}{ Angiography } \\
\hline Vessel score* & 0.60 & $<0.001$ \\
\hline Ejection fraction (\%) & -0.22 & 0.13 \\
\hline Number of smooth lesions & -0.07 & 0.62 \\
\hline
\end{tabular}

turn, can interfere with intracellular signalling pathways known to be influenced by oxidative stress. ${ }^{32}{ }^{33}$ Neopterin activates the redox sensitive transcription nuclear factor $\kappa \mathrm{B},{ }^{34}$ which upregulates proinflammatory genes such as interleukin 6 and tumour necrosis factor $\alpha .^{35}$ The overall result is an increase of the inflammatory tone within the vascular wall. ${ }^{36}$

\section{Widespread inflammation in unstable angina}

Our results confirm and expand previous observations by others $^{11}{ }^{12}{ }^{37}$ that ACS is a pancoronary condition related to

Table 5 Multiple regression analysis with univariate predictive variables for number of complex lesions

\begin{tabular}{|c|c|c|c|}
\hline Variable & B $(95 \% \mathrm{Cl})$ & $t$ & p Value \\
\hline Neopterin (log transformed) & 4.8 (1.9 to 7.7$)$ & 3.4 & 0.002 \\
\hline Vessel score & $0.6(0.03$ to 1.2$)$ & 2.1 & 0.04 \\
\hline \multicolumn{4}{|c|}{$\begin{array}{l}\text { Neutrophil count }(p=0.1), C R P \text { concentration }(p=0.42), L D L \text { cholesterol } \\
(p=0.49) \text {, left ventricular ejection fraction }(p=0.32) \text {, age }(p=0.71) \text {, } \\
\text { systolic blood pressure }(p=0.36) \text {, and treatment with } \beta \text { blockers } \\
\text { ( } p=0.79) \text { and lipid lowering drugs }(p=0.95) \text { were not independent } \\
\text { predictors of complex lesions. } \\
B \text {, increment of the number of complex lesions with every unit of the } \\
\text { independent variable; } C l \text {, confidence interval; } t \text {, statistic of each variable } \\
\text { in the equation. }\end{array}$} \\
\hline
\end{tabular}


the presence of multiple vulnerable plaques. Inflammation and pancoronary plaque vulnerability appear to be directly related and the results of our study give further support to the importance of systemic and local inflammation in multiple atheromatous plaque disruption. Indeed, neutrophil count, neopterin concentration, and CRP concentration were higher in patients with multiple complex lesions than in those with fewer than three complex stenoses. Our findings provide a pathophysiological basis to recent reports by Goldstein et $a l^{7}$ Rioufol et $a l^{12}$ and Asakura et al, ${ }^{37}$ who observed multiple plaque fissuring in patients with ACS. Goldstein et al showed with coronary angiography the existence of additional unstable lesions other than the culprit lesions in $21 \%$ of patients with myocardial infarction. Using intravascular ultrasound, Rioufol et al ${ }^{12}$ found culprit lesion fissuring in over $37 \%$ of patients presenting with a first ACS and troponin I increase. In $79 \%$ of these patients at least one plaque rupture was found in stenoses other than the culprit lesion. Thus, ACS seems to be associated with pancoronary instability. Asakura et al ${ }^{37}$ carried out angioscopic studies in patients undergoing catheterisation one month after the onset of myocardial infarction and observed that all three major coronary arteries were widely diseased and had multiple vulnerable plaques.

Our findings that neutrophil count, neopterin concentration, and CRP concentration are raised in patients with multiple complex stenoses suggest that systemic inflammation may be responsible for this widespread involvement of the coronary tree in patients with ACS. Moreover, our data are in agreement with findings of Buffon et al, ${ }^{11}$ who found generalised activation of neutrophils across the coronary vascular bed in patients with unstable angina, regardless of the location of the culprit stenoses. In agreement with these findings, Naruko et $a l^{38}$ recently found in coronary artery segments from patients with myocardial infarction the occurrence of neutrophil infiltration in ruptured and eroded plaques as well as a higher number of activated neutrophils in patients with ruptured plaques than in patients with eroded plaques.

\section{Limitations of the study}

The present study design did not allow us to determine the mechanisms responsible for higher neutrophil count, CRP concentration, and neopterin concentration in patients with multiple complex lesions compared with those without. However, in the light of results obtained by Buffon et al ${ }^{11}$ and Naruko et al, ${ }^{38}$ it is conceivable that local and systemic inflammation linked to vulnerable plaques could have resulted in raised concentrations of inflammatory markers in our patients. Only a relatively small proportion of patients received statins, probably reflecting standard clinical practice at the time of patient recruitment. Another limitation is that coronary angiography is a "lumenogram" and therefore provides no information regarding phenomena that occur within the vessel wall. Coronary angiography thus has limitations compared with angioscopy and intravascular ultrasound. Moreover, Maehara et al ${ }^{39}$ have recently reported a strong correlation between the angiographic features of coronary plaque rupture and ultrasound findings in patients with unstable and stable coronary syndromes. Waxman et a $l^{40}$ found that angiographically complex atherosclerotic lesions are highly specific markers of plaque instability. Although correlations between inflammatory markers and stenosis morphology are significant in the present study, the clinical significance of this finding requires further investigation.

\section{Conclusions}

Our results indicate a relation between markers of inflammation and pancoronary plaque vulnerability in patients with
ACS. Acute inflammatory markers such as neutrophil count, CRP concentration, and neopterin concentration are higher among patients with multiple angiographically complex plaques than among those without and may help to identify a phenotype with increased plaque vulnerability.

\section{ACKNOWLEDGEMENTS}

This study was supported in part by a grant from the National Heart Research Fund. Drs P Avanzas, R Arroyo, J Cosín, G Aldama, and J Quiles were supported by grants from the Spanish Society of Cardiology. We are grateful to Della Cole for help with patient recruitment and database supervision, and María Lacalle and José María Bellón (Department of Preventative Medicine, Hospital Gregorio Marañón, Madrid, Spain) for expert statistical advice.

\section{Authors' affiliations}

P Avanzas, R Arroyo-Espliguero, J Cosín-Sales, G Aldama, C Pizzi, J Quiles, J C Kaski, Cardiological Sciences, Coronary Artery Disease Research Unit, St George's Hospital Medical School, London, UK

$P$ Avanzas and R Arroyo-Espliguero contributed equally to the study

\section{REFERENCES}

1 Fuster V, Badimon L, Badimon JJ, et al. The pathogenesis of coronary artery disease and the acute coronary syndromes (1). N Engl J Med 1992;326:242-50.

2 Fuster V, Badimon L, Badimon JJ, et al. The pathogenesis of coronary artery disease and the acute coronary syndromes (2). NEngl J Med 1992;326:310-8

3 Gotsman M, Rosenheck S, Nassar H, et al. Angiographic findings in the coronary arteries after thrombolysis in acute myocardial infarction. Am J Cardiol 1992;70:715-23.

4 Davies SW, Marchant B, Lyons JP, et al. Coronary lesion morphology in acute myocardial infarction: demonstration of early remodeling after streptokinase treatment. J Am Coll Cardiol 1990;16:1079-86.

5 Ambrose JA, Winters SL, Arora RR, et al. Coronary angiographic morphology in myocardial infarction: a link between the pathogenesis of unstable angina and myocardial infarction. J Am Coll Cardiol 1985;6:1233-8.

6 Levin DC, Gardiner GA Jr. Complex and simple coronary artery stenoses: a new way to interpret coronary angiograms based on morphologic features of lesions. Radiology 1987; 164:675-80.

7 Goldstein JA, Demetriou D, Grines CL, et al. Multiple complex coronary plaques in patients with acute myocardial infarction. N Engl J Med 2000;343:915-22.

8 Li JJ, Jiang H, Huang CX, et al. Elevated level of plasma C-reactive protein in patients with unstable angina: its relations with coronary stenosis and lipid profile. Angiology 2002;53:265-72.

9 Gupta S, Fredericks S, Schwartzman RA, et al. Serum neopterin in acute coronary syndromes. Lancet 1997;349:1252-3.

10 Garcia-Moll X, Coccolo F, Cole D, et al. Serum neopterin and complex stenosis morphology in patients with unstable angina. J Am Coll Cardiol 2000;35:956-62

11 Buffon A, Biasucci LM, Liuzzo G, et al. Widespread coronary inflammation in unstable angina. N Engl J Med 2002;347:5-12.

12 Rioufol G, Finet G, Ginon I, et al. Multiple atherosclerotic plaque rupture in acute coronary syndrome: a three-vessel intravascular ultrasound study. Circulation 2002;106:804-8.

13 Braunwald E. Unstable angina: a classification. Circulation 1989;80:410-4.

14 Ambrose JA, Winters SL, Stern A, et al. Angiographic morphology and the pathogenesis of unstable angina pectoris. J Am Coll Cardiol 1985;5:609-16.

15 Rehr R, Disciascio G, Vetrovec G, et al. Angiographic morphology of coronary artery stenoses in prolonged rest angina: evidence of intracoronary thrombosis. J Am Coll Cardiol 1989;14:1429-37.

16 Qiao JH, Fishbein MC. The severity of coronary atherosclerosis at sites of plaque rupture with occlusive thrombosis. J Am Coll Cardiol $1991 ; 17: 1138-42$

17 Chen L, Chester MR, Redwood S, et al. Angiographic stenosis progression and coronary events in patients with 'stabilized' unstable angina. Circulation 1995;91:2319-24.

18 Kaski JC, Chester MR, Chen L, et al. Rapid angiographic progression of coronary artery disease in patients with angina pectoris: the role of complex stenosis morphology. Circulation 1995;92:2058-65.

19 Kaski JC, Chen L, Chester M. Rapid angiographic progression of "target" and "nontarget" stenoses in patients awaiting coronary angioplasty. J Am Coll Cardiol 1995;26:416-21.

20 Smith SC Jr, Dove JT, Jacobs AK, et al. ACC/AHA guidelines for percutaneous coronary intervention (revision of the 1993 PTCA guidelines): executive summary. A report of the American College of Cardiology/ American Heart Association task force on practice guidelines (committee to revise the 1993 guidelines for percutaneous transluminal coronary angioplasty) endorsed by the Society for Cardiac Angiography and Interventions. Circulation 2001;103:3019-41. 
21 Zairis M, Papadaki O, Manousakis S, et al. C-reactive protein and multiple complex coronary artery plaques in patients with primary unstable angina. Atherosclerosis 2002; 164:355.

22 Katritsis D, Korovesis S, Giazitzoglou E, et al. C-reactive protein concentrations and angiographic characteristics of coronary lesions. Clin Chem 2001;47:882-6.

23 Sabatine MS, Morrow DA, Cannon CP, et al. Relationship between baseline white blood cell count and degree of coronary artery disease and mortality in patients with acute coronary syndromes: a TACTICS-TIMI 18 (treat angina with aggrastat and determine cost of therapy with an invasive or conservative strategy-thrombolysis in myocardial infarction 18 trial) substudy. J Am Coll Cardiol 2002:40:1761-8.

24 Moreno PR, Falk E, Palacios IF, et al. Macrophage infiltration in acute coronary syndromes: implications for plaque rupture. Circulation 1994;90:775-8.

25 Huber C, Batchelor JR, Fuchs D, et al. Immune response-associated production of neopterin: release from macrophages primarily under control of interferongamma. J Exp Med 1984;160:310-6.

26 Davies MJ. Stability and instability: two faces of coronary atherosclerosis. The Paul Dudley White Lecture 1995. Circulation 1996:94:2013-20.

27 Falk E. Morphologic features of unstable atherothrombotic plaques underlying acute coronary syndromes. Am J Cardiol 1989;63:114E-20E.

28 Libby P. Molecular bases of the acute coronary syndromes. Circulation 1995:91:2844-50.

29 Van der Wal AC, Becker AE, van der Loos CM, et al. Site of intimal rupture or erosion of thrombosed coronary atherosclerotic plaques is characterized by an inflammatory process irrespective of the dominant plaque morphology. Circulation 1994;89:36-44.
30 Galis ZS, Sukhova GK, Lark MW, et al. Increased expression of matrix metalloproteinases and matrix degrading activity in vulnerable regions of human atherosclerotic plaques. J Clin Invest 1994;94:2493-503.

31 Galis ZS, Khatri JJ. Matrix metalloproteinases in vascular remodeling and atherogenesis: the good, the bad, and the ugly. Circ Res 2002;90:251-62.

32 Schobersberger W, Hoffmann G, Grote J, et al. Induction of inducible nitric oxide synthase expression by neopterin in vascular smooth muscle cells. FEBS Lett 1995;377:461-4.

33 Werner-Felmayer G, Werner ER, Fuchs $D$, et al. Pteridine biosynthesis in human endothelial cells: impact on nitric oxide-mediated formation of cyclic GMP. J Biol Chem 1993;268:1842-6.

34 Hoffmann G, Schobersberger W, Frede S, et al. Neopterin activates transcription factor nuclear factor-kappa B in vascular smooth muscle cells. FEBS Lett 1996:391:181-4.

35 Barnes PJ, Karin M. Nuclear factor-kappaB: a pivotal transcription factor in chronic inflammatory diseases. N Engl J Med 1997;336:1066-71.

36 Thurberg BL, Collins T. The nuclear factor-kappa B/inhibitor of kappa B autoregulatory system and atherosclerosis. Curr Opin Lipidol 1998:9:387-96.

37 Asakura M, Ueda Y, Yamaguchi O, et al. Extensive development of vulnerable plaques as a pan-coronary process in patients with myocardial infarction: an angioscopic study. J Am Coll Cardiol 2001;37:1284-8.

38 Naruko T, Ueda M, Haze K, et al. Neutrophil infiltration of culprit lesions in acute coronary syndromes. Circulation 2002;106:2894-900.

39 Maehara A, Mintz GS, Bui AB, et al. Morphologic and angiographic features of coronary plaque rupture detected by intravascular ultrasound. J Am Coll Cardiol 2002;40:904-10.

40 Waxman S. Characterization of the unstable lesion by angiography angioscopy, and intravascular ultrasound. Cardiol Clin 1999;17:295-305.

\section{IMAGES IN CARDIOLOGY}

\section{Impending septal rupture in myocardial infarction detected by cardiac magnetic resonance imaging}

A 67 year old woman was admitted one week after an ambulatory inferior myocardial infarction. Cardiac magnetic resonance imaging (MRI) (1.5 T, Sonata, Maestro class; Siemens, Erlangen, Germany) was performed the next day to assess myocardial viability. Contrast enhanced dynamic myocardial perfusion imaging (TrueFISP-sequence) at rest demonstrated contrast flow from the cavity of the left ventricle into the myocardium near the basal septum (arrows). The contrast agent penetrated about three quarters of the myocardial thickness, thus showing impending myocardial rupture (panel A). Using late enhancement technique (TurboFLASHsequence) 10 minutes after application of contrast agent, an extended transmural inferior infarction could be seen in the long axis view (panel B). Impending myocardial rupture is nontransmural and does not reach the subepicardial fatty tissue $(\dagger)$. Inside the myocardial infarction a zone with hypointense signal represented microvascular obstruction $\left({ }^{*}\right)$. Four hours after the MRI examination the patient
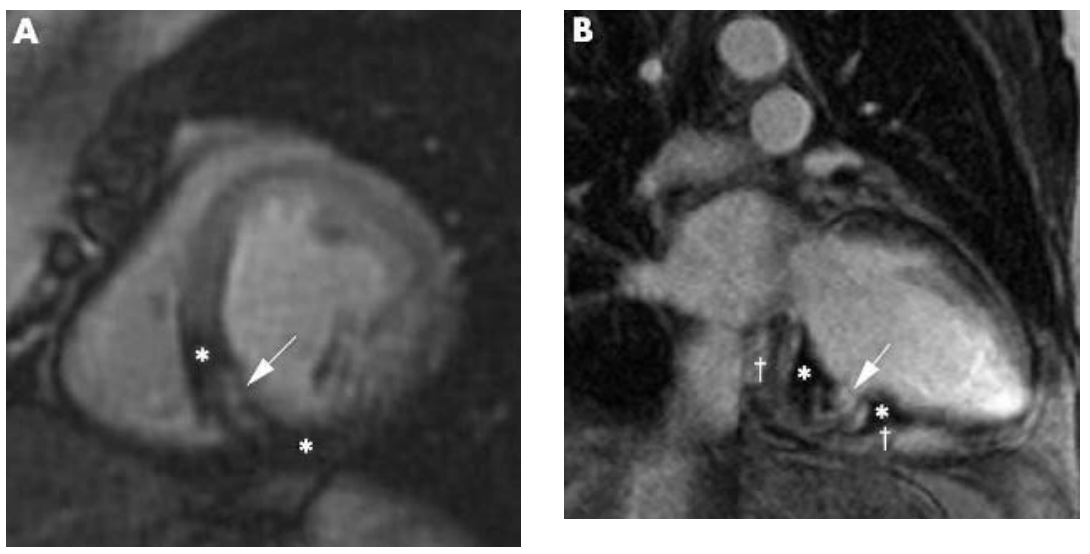

developed cardiogenic shock with a loud systolic murmur. Left ventricular angiography in a left anterior oblique (LAO) $60^{\circ}$ position demonstrated an inferiorly located ventricular septal defect (panel C).

\section{O K Mohrs \\ B Nowak \\ T Voigtlaender mohrs@ccb.de}

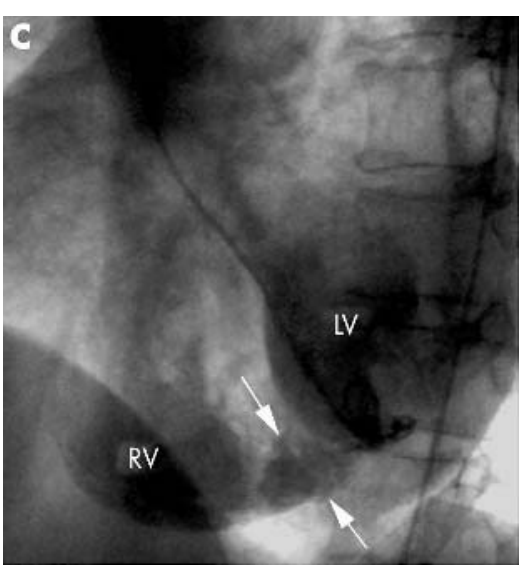

